\title{
Perfil hematológico de bovinos experimentalmente inoculados com veneno de Bothrops alternatus
}

\section{(Blood profile cattle experimentally inoculated with Bothrops alternatus venom)}

\author{
Neide Judith Faria de Oliveira, ${ }^{*}$ Eduardo Lara Ribeiro, ${ }^{*}$ Maria Lúcia, ${ }^{* *}$ Marília Martins Melo*
}

\begin{abstract}
Resumo
Apesar de ser alto o número de acidentes ofídicos em bovinos, as alterações hematológicas e bioquímicas séricas são pouco estudadas, especialmente nas três primeiras semanas após o envenenamento. Diante deste contexto, objetivou-se nesta pesquisa caracterizar o perfil hematológico e bioquímico sérico de bovinos após a inoculação experimental do veneno de Bothrops alternatus. Cinco novilhas mestiças de peso corporal entre 188 e 278kg e idade de 12 a 18 meses receberam na altura média da face cranial do membro anterior direito, entre as articulações umerorradioulnar e do carpo, por via intramuscular superficial, $0,15 \mathrm{mg} / \mathrm{kg}$ de veneno de Bothrops alternatus diluído em salina. Coletou-se sangue de todos os animais antes (tempo zero) e as 3, 8, 24, 48, 72, 96, 168, 240, 405 e 576 horas após inoculação do veneno para avaliação do hemograma, coagulograma e dosagem de proteína total, albumina, globulinas, ureia, creatinina, creatina fosfotransferase, aspartato aminotransferase e gama glutamiltransferase. O veneno de $B$. alternatus causou intoxicação grave nos bovinos, e foi letal para dois animais às 53 horas e 78 horas. As alterações hematológicas observadas foram: anemia normocítica normocrômica, leucocitose com neutrofilia com desvio para esquerda regenerativo, linfocitose, aumentos dos tempos de coagulação, de protrombina e de tromboplastina parcial ativada, trombocitopenia e elevação da ureia e das enzimas CPT e AST.
\end{abstract}

Palavras-chave: bovino, Bothrops alternatus, perfil hematológico, bovinos, envenenamento.

\begin{abstract}
Despite the high number of Bothrops envenomation in cattle, the hematological and biochemical changes are poorly known mainly in the first few weeks after the poisoning. In this context, the aim of this study was to evaluate the bovine blood profile after $B$. alternatus envenomation. Five crossbred heifers were inoculated with $B$. alternatus venom $(0.15 \mathrm{mg} / \mathrm{kg})$ diluted in saline solution, by intramuscular injection, in the mean height of the cranial side of right forelimb, between the joints umerradio-ulnar and carpus. The blood was collected before the beginning of the experiment (zero time) and at 3, 8, 24, 48, 72, 96, $168,240,405$ e 576 hours after inoculation, in order to evaluate the hemogram, coagulogram, total protein, albumine, globulins, urea, creatinine, creatinine phosphokinase (CPT) and aspartate aminotransferase. The $B$. alternatus venon caused a serious envenomation in catlle and was lethal for two animals at 53 and 78 hours. The blood profile alteratons were normocitic and normocromic anaemia, leucocitosis with neutrophilia, linfocitosis, coagulation time increased, trombocytopenia and elevation in the urea, CPT and AST enzymes.
\end{abstract}

Keywords: Bothrops alternatus, bovine, blood profile, envenomation.

\section{Introdução}

A serpente Bothrops alternatus, conhecida como urutu cruzeira ou boicotiara possui um dos venenos botrópicos mais letais, sendo o terceiro mais tóxico entre as serpentes, após Crotalus durissus terrificus e B. jararaca (Roodt et al., 2000).

Existem poucos estudos epidemiológicos na Medicina Veterinária (Ferreira Jr. e Barraviera, 2004) e as espécies de animais domésticos mais sensíveis ao veneno botrópico são, em ordem decrescente: bovinos, equinos, ovinos, caninos, suínos e felinos (Araújo e Belluomini, 1960-62). Bovinos adultos são mais resistentes que os jovens e as picadas de serpentes ocorrem com maior frequência nos membros e na região da cabeça (Biondo et al., 1993; Menezes, 1995).

Venenos botrópicos alteram o hemograma, como consequência da ação trombina-símile, da atuação sobre a agregação plaquetária, da ativação dos fatores da coagulação e da toxicidade vascular de frações do veneno, ocorrendo hemoconcentração transitória. Porém, devido à diátese hemorrágica instalada local e sistemicamente, é evidente a anemia severa que ocorre posteriormente (Theakston e Kamiguti, 1998).

\footnotetext{
* Escola de Veterinária - Universidade Federal de Minas Gerais. Caixa Postal 567 - 30123-970 - Belo Horizonte, MG.

** Departamento de Biologia - UNIFENAS - Alfenas, MG
} 
O veneno botrópico causa hemólise in vitro (Kellen et al., 1960-62; Rosenfeld et al., 1960-62) e as fosfolipases $A_{2}\left(P_{2} A_{2}\right)$ presentes no veneno, além da citotoxicidade vascular e coagulação intravascular disseminada (CID) podem predispor a hemólise descrita em camundongos (Chaves et al., 1992) e cães (Santos et al., 2003).

A extensa inflamação local causada no envenenamento botrópico influencia o leucograma de cães, resultando em leucocitose, neutrofilia e desvio a esquerda regenerativo (Santos et al., 2003, Ferreira Jr. e Barraviera, 2004).

O veneno botrópico ativa a hemostasia, provocando coagulopatia e trombopatia (Tanjoni et al., 2003), mais severas em picadas de serpentes jovens. Os acidentes botrópicos provocam incoagulabilidade sanguínea, hipofibrinogenemia, aumento dos produtos de degradação da fibrina e fibrinogênio (PDFs) e redução da antiplasmina; prolongamentos dos tempos de protrombina (TP), de tromboplastina parcial ativada (TTPA) e de coagulação (TC), além do consumo dos fatores de coagulação V e VIII (Bogarin et al., 2000, Jácome et al., 2002).

Os efeitos locais e sistêmicos do veneno botrópico em diferentes órgãos e tecidos determinam as alterações bioquímicas séricas (Otero et al., 2002).

Apesar de existirem diversas pesquisas sobre as frações dos venenos e seus efeitos (Oliveira et al., 2007), a literatura é escassa quanto aos achados laboratoriais dos envenenamentos ofídicos, especialmente nos bovinos. Provavelmente, nesses, a maioria dos acidentes ofídicos seja causada por serpentes do gênero Bothrops (Ferreira Jr. e Barraviera, 2004).

Considerando que o bovino é uma das espécies mais sensíveis ao veneno ofídico, e que a sua taxa Mielóide: Eritróide é menor que 1, buscou-se nesta pesquisa caracterizar o perfil hematológico e bioquímico de bovinos após a inoculação experimental do veneno de Bothrops alternatus.

\section{Material e métodos}

O experimento foi conduzido no Hospital Veterinário da Escola de Veterinária da UFMG onde os animais ficaram alojados em galpão de alvenaria, contidos num sistema tipo tie stall, recebendo dieta balanceada composta por ração comercial para novilhas $^{1}$ e silagem de milho, água e mistura mineral ${ }^{2}$ ad libitum.

Foram utilizadas cinco novilhas mestiças das raças Holandês/Zebu, peso corporal entre 188 a $278 \mathrm{~kg}$ e idade de 12 a 18 meses, previamente desverminadas com ivermectina ${ }^{3} \mathrm{e}$ vacinadas contra febre aftosa, ${ }^{4}$ raiva ${ }^{5}$ e clostridioses ${ }^{6}$ com as doses determinadas pelo fabricante.

$O$ veneno cristalizado da serpente de $B$. alternatus foi armazenado a $-20^{\circ} \mathrm{C}$ e ressuspendido em solução salina
$(0,9 \%)^{7}$ para a inoculação nos bovinos. Injetou-se $0,15 \mathrm{mg} /$ $\mathrm{kg}$ do veneno por $\mathrm{kg}$ de peso corporal segundo Araújo e Belluomini (1963), por via intramuscular superficial, na face cranial do membro anterior direito, entre as articulações umerorradioulnar e do carpo. Para garantir a penetração exata em todos os animais, as agulhas foram introduzidas na profundidade de $6 \mathrm{~mm}$, usando dispositivo de esparadrapo adaptado à agulha, conforme técnica utilizada por Lago et al. (2001).

Nos tempos antes (0h) e depois da inoculação do veneno (3, $8,24,48,72,96,168,240,408$ e 576 horas) coletou-se sangue por punção da veia jugular, com agulha e tubos tipo vacutainer que foi acondicionado em: (a) tubo contendo sal dissódico do ácido etileno diaminotetracético (EDTA) a 10\% para realização do eritrograma e da contagem do número de leucócitos; (b) tubo contendo citrato de sódio a 10\%, para realização do Tempo de Protrombina (TP), Tempo de Tromboplastina Parcial Ativada (TTPa) e fibrinogênio; (c) tubo sem anticoagulante para avaliar o Tempo de Coagulação (TC) a $37^{\circ} \mathrm{C}$ e (d) tubo sem anticoagulante para a obtenção do soro destinado às análises bioquímicas.

A contagem de eritrócitos leucócitos totais, dosagem de hemoglobina, determinação do volume globular e cálculo dos índices hematimétricos: volume globular médio (VGM), hemoglobina globular média (HGM) e concentração de hemoglobina globular média (CHGM) foram realizadas em contador eletrônico. ${ }^{8}$

As plaquetas (método indireto de Fonio) e a contagem diferencial de leucócitos foram feitas nos esfregaços sanguíneos depois de fixados e corados por May GrunwaldGiemsa. Utilizou-se a colorimetria ${ }^{9}$ para a dosagem de asparto aminotransferase (AST), creatina fosfotransferase (CPT), gama glutamiltransferase (GGT), proteína total (PT) e albumina, e por diferença entre a PT e albumina, obtiveramse as globulinas (Thrall, 2003).

Mediram-se TP e TTPA pela coagulação do plasma nos métodos de Quick modificado ${ }^{10}$ e pela formação do coágulo plasmático na presença de ativador e fosfolípides recalcificados com cloreto de cálcio, ${ }^{11}$ respectivamente. Estimou-se por colorimetria o fibrinogênio, pelo método de Ratnoff e Menzie (1959) modificado e o TC, segundo Lee e White (1913).

O experimento, delineado em blocos ao acaso, teve no tempo zero uma linha basal de referência, sendo os animais (blocos) seus próprios controles e os horários antes e depois da inoculação, os tratamentos, numa resposta de fluxo continuado. Todos os dados obtidos foram submetidos a análise de variância normal e de regressão, utilizando-se os sistemas para análises estatísticas com o Softwear SAS e SAEG. As médias foram comparadas utilizando-se os testes de Student-Newman-Keuls ao nível de $5 \%$ de probabilidade conforme Sampaio (2007).

\footnotetext{
${ }^{1}$ Ração Novilhas Itambé ${ }^{\circledR}$ 16\%PB

2 Fosbovi $20 \circledR$, Tortuga.

${ }^{3}$ Ranger ${ }^{\circledR}$ - Vallée S A - Produtos Veterinários.

${ }^{4}$ Bovicel ${ }^{\circledR}$ - Vallée S A - Produtos Veterinários.

${ }^{5}$ Raivacel ${ }^{\circledR}$ - Vallée S A - Produtos Veterinários.

${ }^{6}$ Polistar ${ }^{\circledR}$ - Vallée S A - Produtos Veterinários.
}

\footnotetext{
${ }^{7}$ Cloreto de sódio 0,9\% - Hypofarma.

${ }^{8}$ VET ABX $\mathrm{TM}$ - Diagnostics.

${ }^{9}$ Bioclin- Kits comerciais

${ }_{10}$ Fischer Diagnostics

${ }^{11}$ Human In vitro Diagnóstica/SA
} 


\section{Resultados e discussão}

Observou-se hemólise macroscópica às 24 e 48 horas após a inoculação experimental do veneno de $B$. alternatus em todos os bovinos deste experimento. A hemólise também foi descrita em cães (Sano-Martins et al., 1995; Takahira, 1999; Santos et al., 2003) e em ratos expostos ao veneno botrópico (Chaves et al., 1992). O aumento da fragilidade eritrocitária e a hemólise indireta no envenenamento botrópico podem ser causados

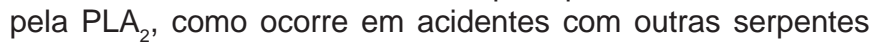
(Segev et al., 2004), alterações vasculares tóxicas, distúrbios hemodinâmicos da coagulação intravascular disseminada (CID) e ativação do sistema do complemento (Farsky et al., 2000), apesar de o efeito hemolítico direto ser comprovado apenas in vitro (Kellen et al., 1960; Rosenfeld et al., 1960-62).

Dois animais vieram a óbito às 53 e 78 horas após a inoculação do veneno de $B$. alternatus. Verificou-se anemia severa em dois dias e normalização dez dias depois do envenenamento. Conforme Feldman et al. (2000) este tempo é necessário para maturação das células vermelhas do bovino. Nos primeiros dias, como esperado após a anemia aguda regenerativa, foram vistas policromasia e macrocitose.
Apesar de terem sido verificadas variações nos índices hematimétricos, não foram observadas microcitose ou hipocromia nos esfregaços sanguíneos destes bovinos, caracterizando a anemia apresentada como normocítica e normocrômica até 96 horas, corroborando os achados de Takahira (1999) e Santos et al. (2003) em cães expostos a diferentes venenos botrópicos. Possivelmente houve proliferação eritróide medular, como resposta à hipóxia tecidual e ainda pode ter ocorrido estímulo eritropoiético associado a frações do veneno botrópico, conforme descrito em camundongos por Maria et al. (2003).

Os resultados demonstram que nos bovinos expostos ao veneno de $B$. alternatus foi constatada redução $(P \leq 0,05)$ da contagem de eritrócitos, volume globular e concentração de hemoglobina, de 48 horas a 168 horas após a inoculação (Tabela 1), comprovando a anemia grave, devido à perda sanguínea aguda provocada pela diátese hemorrágica instalada local e sistemicamente no envenenamento botrópico, como descrito em ratos (Pérez et al., 1998), seres humanos (Otero et al., 2002) e em cães (Santos et al., 2003; Ferreira Jr. e Barraviera, 2004).
Ocorreu pequena elevação no número de eritrócitos até 24 horas e queda significativa 48 horas após a inoculação do veneno (Tabela 1). Este aumento relaciona-se ao estresse e a dor local, devido à ação de catecolaminas, indicando policitemia relativa nas primeiras horas do envenenamento botrópico. Relatou-se hemoconcentração transitória em diferentes envenenamentos ofídicos em vários estudos (Franceschi, 1990; Lago et al., 2001; Segev et al., 2004). Posteriormente, no tempo 72 horas, há indicativo da perda de sangue abrupta e exaustão das reservas esplênicas e medulares (Chen et al., 2004).

Os menores valores de eritrócitos, volume globular e concentração de hemoglobina foram observados às 96 horas pós inoculação. A redução persiste nos tempos 168 e 240 horas, e há aumento significativo às 240 horas, porém, o retorno aos níveis basais de eritrócitos acontece somente no 17으 dia (408 horas).

As maiores médias do VGM foram observadas às 168 horas, permane-cendo elevadas $(\mathrm{P} \leq 0,05)$ até 576 horas (Tabela 1$)$. Este resultado demonstra a macrocitose a partir de 168 horas, achado comum nas anemias regenerativas (Feldman et al., 2000). Houve redução da HGM até 96 horas pós-inoculação e aumento nos tempos seguintes até 240 horas. Sete dias após a inoculação do veneno (168 horas), houve nos animais diminuição significativa dos valores médios de CHGM. Posteriormente, a absorção de eritrócitos agregados nos trombos formados e a resposta regenerativa à perda sanguínea aguda mantêm o CHGM em níveis mais elevados até 168 horas. $P \leq 0,05)$
Tabela 1: Valores médios do número de eritrócitos (/mm3), volume globular (\%), hemoglobina $(\mathrm{g} / \mathrm{dl})$, volume globular médio $(\mathrm{fl})$, hemoglobina globular média (pg) e concentração de hemoglobina globular média (\%) em bovinos antes e após a inoculação do veneno de $B$. alternatus $0,15 \mathrm{mg} / \mathrm{kg}$ do veneno por $\mathrm{kg}$ de peso corporal

\begin{tabular}{ccccccc}
\hline Variáveis & $\begin{array}{c}\text { Eritrócitos } \\
/ \mathrm{mm}^{3}\end{array}$ & $\begin{array}{c}\text { Volume } \\
\text { globular } \%\end{array}$ & $\begin{array}{c}\text { Hemoglobina } \\
\text { g/dl }\end{array}$ & $\begin{array}{c}\text { VGM } \\
\mathrm{fl}\end{array}$ & $\begin{array}{c}\text { VGM } \\
\text { pg }\end{array}$ & $\begin{array}{c}\text { CHGM } \\
\%\end{array}$ \\
\hline Tempos & & & & & & \\
T0h & $6.610 .000 \mathrm{c}$ & $26,36 \mathrm{c}$ & $8,89 \mathrm{bc}$ & $40,23 \mathrm{~d}$ & $13,59 \mathrm{~cd}$ & $33,78 \mathrm{a}$ \\
T3h & $7.790 .000 \mathrm{ab}$ & $29,70 \mathrm{ab}$ & $9,77 \mathrm{ab}$ & $38,67 \mathrm{e}$ & $12,63 \mathrm{e}$ & $32,80 \mathrm{abc}$ \\
T8h & $7.450 .000 \mathrm{bc}$ & $28,33 \mathrm{bc}$ & $9,20 \mathrm{ab}$ & $38,33 \mathrm{e}$ & $12,43 \mathrm{e}$ & $32,40 \mathrm{abc}$ \\
T24h & $8.410 .000 \mathrm{a}$ & $32,37 \mathrm{a}$ & $10,50 \mathrm{a}$ & $38,67 \mathrm{e}$ & $12,57 \mathrm{e}$ & $32,50 \mathrm{abc}$ \\
T48h & $5.310 .000 \mathrm{~d}$ & $20,33 \mathrm{~d}$ & $6,63 \mathrm{~d}$ & $38,67 \mathrm{e}$ & $12,53 \mathrm{e}$ & $32,63 \mathrm{abc}$ \\
T72h & $4.030 .000 \mathrm{e}$ & $15,53 \mathrm{e}$ & $5,23 \mathrm{e}$ & $38,67 \mathrm{e}$ & $12,93 \mathrm{e}$ & $33,70 \mathrm{ab}$ \\
T96h & $3.740 .000 \mathrm{e}$ & $14,57 \mathrm{e}$ & $4,93 \mathrm{e}$ & $38,67 \mathrm{e}$ & $13,13 \mathrm{de}$ & $33,87 \mathrm{a}$ \\
T168h & $4.100 .000 \mathrm{e}$ & $20,80 \mathrm{~d}$ & $6,70 \mathrm{~d}$ & $50,67 \mathrm{a}$ & $16,47 \mathrm{a}$ & $32,40 \mathrm{bc}$ \\
T240h & $5.590 .000 \mathrm{~d}$ & $25,50 \mathrm{c}$ & $8,07 \mathrm{c}$ & $45,67 \mathrm{~b}$ & $14,50 \mathrm{~b}$ & $31,63 \mathrm{~cd}$ \\
T408h & $7.030 .000 \mathrm{bc}$ & $31,23 \mathrm{ab}$ & $9,63 \mathrm{ab}$ & $44,33 \mathrm{bc}$ & $13,73 \mathrm{c}$ & $30,90 \mathrm{~d}$ \\
T576h & $7.640 .000 \mathrm{ab}$ & $32,63 \mathrm{a}$ & $9,60 \mathrm{ab}$ & $43,00 \mathrm{c}$ & $12,67 \mathrm{e}$ & $29,30 \mathrm{e}$ \\
\hline
\end{tabular}

Médias seguidas de letras minúsculas iguais não diferem estatisticamente entre os tempos (Teste SNK

A perda sanguínea aguda grave observada no envenenamento botrópico ocorre devido à ação trombina símile do veneno (Kamiguti et al. 1994), alteração da agregação plaquetária reportada por Castro et al. (1998 e 1999) e da ação vasculotóxica sistêmica das hemorraginas e outras frações (Kamiguti et al., 1996; Tanjoni et al., 2003).

$\mathrm{Na}$ morfologia celular eritróide, o animal no 1 evoluiu para a morte 53 horas pós-inoculação e apresentou anisocitose às 24 e 48 horas, sendo verificados macrocitose, policromasia, pontilhados basofílicos, corpúsculos de Howell Jolly, metarrubrócitos (2/100 leucócitos) e rubrócitos (2 /100 leucócitos) às 48 horas. 
O animal ํo 2 apresentou entre 24 a 72 horas anisocitose, policromasia, presença de corpúsculos de Howell Jolly e pontilhados basofílicos, além de rubrócitos (5/100 leucócitos), metarrubrócitos (11/100 leucócitos), rubiblasto e hematogônia e morreu às 78 horas. $O$ bovino $\mathrm{n} 03$ apresentou anisocitose entre 8 a 576 horas, com presença de pontilhados basofílicos e corpúsculos de Howell Jolly de 48 a 168 horas e policromasia neste tempo.

No bovino no4 observou-se anisocitose de 8 horas até 576 horas. Entre 8 e 168 horas houve poiquilocitose e policromasia, corpúsculos de Howell Jolly e pontilhados basofílicos. Foram verificados rubrócitos (1/100 leucócitos às 8 e 24 horas, 2/100 leucócitos às 48 horas) e metarrubrócitos (1/ 100 leucócitos em 24 horas e 168 horas, 1/100 leucócitos em 48 e 96 horas e 4/100 leucócitos em 72 horas).

$O$ animal $n^{\circ} 5$ demonstrou anisocitose entre 48 e 576 horas, poiquilocitose e policromasia moderada, macrocitose, corpúsculos de Howell Jolly e pontilhados basofílicos de 48 a 168 horas. Entre 240 e 408 horas ocorreu poiquilocitose, policromasia, macrocitose e raros corpúsculos de Howell Jolly. Indentificaram-se rubrócitos (2/100 leucócitos em 48 e 72 horas) e metarrubrócitos (3/100 leucócitos em 48 horas e 2/100 leucócitos em 72 horas).

O eritrograma indica que em três bovinos ocorreu liberação de células eritróides jovens para a circulação e destes, um sucumbiu, vítima dos efeitos deletérios do veneno botrópico. Dois animais não responderam a anemia e destes, um sobreviveu e outro veio a óbito. Pelo exame da extensão sanguínea, ocorreram diferentes respostas à anemia causada pelo envenenamento botrópico e os animais com cura espontânea demonstraram menos alterações ou resposta mais precoce. A presença de células jovens da linhagem eritróide indica que os bovinos apresentavam anemia, com resposta medular regenerativa e possivel-mente, com a liberação de reticulócitos evidenciada pela policromasia, anisocitose, macrocitose e elevação do VGM entre 168 e 576 horas.

As médias de leucócitos totais $/ \mathrm{mm}^{3}$ de sangue variaram entre 12.663 (0h) e 29.400 às 8 horas. Entre 3 às 48 horas os valores são superiores $(P \leq 0,05)$ aos basais, igualando-se a este 72 horas após a inoculação do veneno de $B$. alternatus (Tabela 2). Especialmente em bovinos, este resultado indica que o veneno botrópico atua como um grande estímulo inflamatório, mobilizando as células brancas dos compartimentos marginais e de reserva (Arruda et al., 2003; Chacur et al., 2003).

A leucocitose no envenenamento botrópico pode ser resultante da ação da bradicinina, das metaloproteinases do veneno, que potencializam a inflamação e relaciona-se ainda à dor e ao estresse, sendo também descrita em seres humanos (Barraviera et al., 1995) e em cães (Pérez et al., 1997; Jácome et al., 2002).

Os bovinos apresentaram contagens médias de neutrófilos bastonetes $/ \mathrm{mm}^{3}$ de sangue entre 141,0 (0h) e 509,33 (24 horas), ultrapassando os limites superiores descritos por Feldman et al. (2000) entre 3 a 72 horas (Tabela 2). Foram identificadas células jovens da linhagem mielóide em todos os bovinos: no animal oㅜ 3, 280 metamielócitos as 24 horas e 180 as 96 horas; no bovino no 4, 816 metamielócitos às 3 horas e 888 às 24 horas; e no animal no5, 324 metamielócitos às 48 horas. Estes resultados indicam que a resposta mielóide foi menor e mais tardia nos bovinos que sucumbiram devido aos efeitos do veneno.

As médias de neutrófilos segmentados $/ \mathrm{mm}^{3}$ de sangue oscilaram entre 3.032 (0h) e 15.800 (8 horas) e quintuplicaram-se em apenas 8 horas (Tabela 2). Os valores são superiores $(P \leq 0,05)$ ao tempo zero entre 3 às 24 horas $e$ somente em 0, 408 e 576 horas encontram-se dentro do limite para a espécie (Feldman et al., 2000). Diagnosticouse neutrofilia em bovinos até 10 dias depois da inoculação do veneno de $B$. alternatus, concordando com os achados em camundongos (Farsky et al., 1997 e 2000) e em cães (Sano-Martins et al., 1995; Takahira, 1999) submetidos ao envenenamento botrópico.

O número médio de linfócitos $/ \mathrm{mm}^{3}$ de sangue variou entre 6.536 (96 horas) a 15.981 ( 3 horas) (Tabela 2), sendo os valores superiores $(P \leq 0,05)$ aos basais entre 3 às 24 horas (linfocitose) e similares após 48 horas. Entretanto, SanoMartins et al. (1995), Takahira (1999) e Santos et al. (2003) encontraram linfocitopenia em cães expostos ao veneno botrópico.

As médias de monócitos, eosinófilos e basófilos $/ \mathrm{mm}^{3} \mathrm{de}$ sangue variaram entre 774 ( 8 horas) e 256 (168 horas), 174 (96 horas) e 447 (168 horas) e zero (3 horas) e 250,67 (24 horas) e todas se encontram dentro da faixa normal para a espécie (Feldman et al., 2000), de acordo com a Tabela 2.

Tabela 2: Valores médios do número de leucócitos, neutrófilos bastonetes, neutrófilos segmentados, linfócitos, monócitos, eosinófilos e basófilos $/ \mathrm{mm}^{3}$ em bovinos antes e após a inoculação do veneno de $B$. alternatus $0,15 \mathrm{mg} / \mathrm{kg}$ do veneno por $\mathrm{kg}$ de peso corporal

\begin{tabular}{lccccccc}
\hline Variáveis & $\begin{array}{c}\text { Leucócitos/ } \\
\mathrm{mm}^{3}\end{array}$ & $\begin{array}{c}\text { Bastonetes/ } \\
\mathrm{mm}^{3}\end{array}$ & $\begin{array}{c}\text { Segmentados/ } \\
\mathrm{mm}^{3}\end{array}$ & $\begin{array}{c}\text { Linfócitos/ } \\
\mathrm{mm}^{3}\end{array}$ & $\begin{array}{c}\text { Monócitos/ } \\
\mathrm{mm}^{3}\end{array}$ & $\begin{array}{c}\text { Eosinófilos/ } \\
\mathrm{mm}^{3}\end{array}$ & $\begin{array}{c}\text { Basófilos/ } \\
\mathrm{mm}^{3}\end{array}$ \\
\hline Tempo & & & & & & & \\
T0h & $12.663 \mathrm{c}$ & $141,00 \mathrm{a}$ & $3032,00 \mathrm{~d}$ & $8678,67 \mathrm{~cd}$ & $539,00 \mathrm{a}$ & $252,67 \mathrm{a}$ & $2,67 \mathrm{~b}$ \\
T3h & $27.333 \mathrm{a}$ & $459,33 \mathrm{a}$ & $9698,67 \mathrm{c}$ & $15981,33 \mathrm{a}$ & $630,67 \mathrm{a}$ & $168,00 \mathrm{a}$ & $0,00 \mathrm{~b}$ \\
T8h & $29.400 \mathrm{a}$ & $417,33 \mathrm{a}$ & $15800,67 \mathrm{a}$ & $12196,67 \mathrm{~b}$ & $774,00 \mathrm{a}$ & $205,33 \mathrm{a}$ & $0,00 \mathrm{~b}$ \\
T24h & $26.933 \mathrm{a}$ & $509,33 \mathrm{a}$ & $12450,67 \mathrm{~b}$ & $13128,00 \mathrm{~b}$ & $269,33 \mathrm{a}$ & $269,33 \mathrm{a}$ & $250,67 \mathrm{a}$ \\
T48h & $17.933 \mathrm{~b}$ & $231,33 \mathrm{a}$ & $6760,67 \mathrm{~d}$ & $10084,00 \mathrm{c}$ & $371,33 \mathrm{a}$ & $244,67 \mathrm{a}$ & $101,33 \mathrm{ab}$ \\
T72h & $15.367 \mathrm{bc}$ & $351,00 \mathrm{a}$ & $6338,00 \mathrm{~d}$ & $8055,67 \mathrm{~cd}$ & $461,00 \mathrm{a}$ & $202,33 \mathrm{a}$ & $204,67 \mathrm{ab}$ \\
T96h & $14.767 \mathrm{bc}$ & $121,33 \mathrm{a}$ & $5969,33 \mathrm{~d}$ & $6536,00 \mathrm{~d}$ & $623,00 \mathrm{a}$ & $147,67 \mathrm{a}$ & $130,67 \mathrm{ab}$ \\
T168h & $13.067 \mathrm{c}$ & $102,33 \mathrm{a}$ & $4115,67 \mathrm{~d}$ & $7893,33 \mathrm{~cd}$ & $256,00 \mathrm{a}$ & $447,33 \mathrm{a}$ & $70,00 \mathrm{ab}$ \\
T240h & $13.200 \mathrm{c}$ & 37,33 & $4144,33 \mathrm{~d}$ & $8108,33 \mathrm{~cd}$ & $563,67 \mathrm{a}$ & $337,00 \mathrm{a}$ & $76,33 \mathrm{ab}$ \\
T408h & $12.800 \mathrm{c}$ & $119,33 \mathrm{a}$ & $3478,67 \mathrm{~d}$ & $8354,67 \mathrm{~cd}$ & $512,00 \mathrm{a}$ & $297,67 \mathrm{a}$ & $37,67 \mathrm{~b}$ \\
T576h & $14.200 \mathrm{c}$ & $244,00 \mathrm{a}$ & $3590,67 \mathrm{~d}$ & $9455,33 \mathrm{~cd}$ & $546,00 \mathrm{a}$ & 174,67 & $0,00 \mathrm{~b}$ \\
\hline
\end{tabular}

Médias seguidas de letras minúsculas iguais não diferem estatisticamente entre os tempos (Teste $S N K P \leq 0,05$ ). 
A morfologia celular demonstrou alterações até 576 horas em todos os bovinos. Identificaram-se: neutrófilos segmentados com vacuolizações citoplasmáticas, citoplasma basofílico e corpúsculos de Döhle; linfócitos com citoplasma basofílico, granulações tóxicas e vacúolos citoplasmáticos e nucleares, além de sombras de Grumprecht, indicativas de degeneração leucocitária; linfócitos em divisão às 24 horas em dois bovinos. No bovino no 1 às 72 horas diagnosticaram-se cariorrexe nuclear, granulações tóxicas, basofilia e vacúolos citoplasmáticos e nucleares em linfócitos.

Vacuolizações citoplasmáticas em megacariócitos foram relatadas em cães após envenenamento botrópico (Takahira, 1999) e metaloproteinases e PLA 2 do veneno são citotóxicas, justificando as alterações citotóxicas observadas nos leucócitos de bovinos expostos ao veneno de $B$. alternatus.

Apesar de diferenças individuais ocorrerem na resposta inflamatória frente ao veneno botrópico (Carneiro et al., 2002), as alterações discutidas anteriormente demonstram a toxicidade do veneno de $B$. alternatus sobre o leucograma bovino.

As médias de plaquetas $/ \mathrm{mm}^{3}$ de sangue (Tabela 3) apresentaramse entre 556.453 (240 horas) a 68.017 (24 horas), demonstrando trombocitopenia, com redução significativa às 3 horas e valores abaixo dos normais às 24 e 48 horas, com retorno aos níveis basais somente dez dias após, indicando a resposta medular de reposição apropriada nestes bovinos (Feldman et al., 2000).

A trombocitopenia também foi relatada nos acidentes botrópicos em seres humanos (Sano-Martins et al., 1997; Castro et al., 1999) e em cães (Santos et al., 2003). Os sangramentos nos locais de punção venosa, em mucosas e feridas cutâneas recentes, observados nestes bovinos estão relacionados com a trombocitopenia (Grubbs et al., 1997).

Ressalta-se que as serinoproteases (hemorraginas) e a PLA ${ }_{2}$ presentes no veneno botrópico interferem na adesão e agregação plaquetária, provocando trombopatia e trombocitopenia (Sugiki et al., 1995; Francischetti et al., 1998).

Os valores médios do fibrinogênio nos bovinos são similares entre os tempos (Tabela 3), variam entre 491 (0h) e 775 mg/ $\mathrm{d} \ell$ (240 horas) e estão dentro da faixa de referência para a espécie, de acordo com Kaneko et al. (1997). A tendência ao aumento no fibrinogênio 3 horas pós-inoculação confirma a hipercoagulabilidade inicial causada pela fração trombina símile do veneno botrópico. As médias reduzem às 8 e 24 horas, indicando consumo do fibrinogênio provocado pelo veneno botrópico (Pérez et al., 1997). Das 48 às 240 horas os valores elevam-se, demonstrando a recuperação da concentração de fibrinogênio. SNK $\mathrm{P} \leq 0,05)$
Entretanto, hipofibrinogenemia foi descrita em seres humanos e animais expostos ao veneno botrópico (Cardoso, 1990; Pérez et al., 1997, Santos et al., 2003). Porém, no envenenamento botrópico, dois fatores paradoxais atuam sobre o fibrinogênio plasmático: a fração trombina símile do veneno induz a coagulação instável deste, consumindo-o e a síntese hepática e indução inflamatória (Murata et al., 2004), devido aos efeitos locais do veneno botrópico, justifica-se a ausência de hipofibrinogenemia nos bovinos submetidos ao veneno de $B$. alternatus.

Os valores médios da TTPA (seg) oscilaram entre de 52,67 (576 horas) e 196,33 (24 horas) (Tabela 3) e apenas nesse tempo o resultado foi diferente $(P \leq 0,05)$, indicando 0 prolongamento do TTPA em bovinos, semelhante ao descrito no acidente botrópico em seres humanos (Holloway e Parry, 1989), devido à interferência nos fatores da coagulação causada por frações do veneno botrópico que induzem a formação de trombina intravascular e consumo da protrombina, fator X e outros (Markland, 1998), pois o TTPA prolongado indica defeitos no sistema intrínseco e via comum da coagulação (Grubbs et al., 1997).

Tabela 3: Valores médios do número de plaquetas $\left(/ \mathrm{mm}^{3}\right)$, fibrinogênio $(\mathrm{mg} / \mathrm{dl})$, tempo de tromboplastina parcial ativada (TTPA) em segundos, tempo de protrombina (TP) em segundos e tempo de coagulação (TC) em minutos e segundos, em bovinos antes e após a inoculação do veneno de $B$. alternatus $0,15 \mathrm{mg} / \mathrm{kg}$ do veneno por $\mathrm{kg}$ de peso corporal

\begin{tabular}{lccccc}
\hline Variável & $\begin{array}{c}\text { Plaquetas/m } \\
\mathrm{m}^{3}\end{array}$ & $\begin{array}{c}\text { Fibrinogênio } \\
\mathrm{mg} / \mathrm{dl}\end{array}$ & $\begin{array}{c}\text { TTPa } \\
\text { segundos }\end{array}$ & $\begin{array}{c}\text { TP } \\
\text { segundos }\end{array}$ & $\begin{array}{c}\text { TC } \\
\text { minutos } \\
\text { e segundos }\end{array}$ \\
\hline Tempo & & & & & \\
T0h & $411.950 \mathrm{ab}$ & $491,00 \mathrm{a}$ & $56,53 \mathrm{~b}$ & $22,50 \mathrm{c}$ & $4 \mathrm{~min}$ e $5 \mathrm{~s} \mathrm{~d}$ \\
T3h & $214.317 \mathrm{~cd}$ & $573,33 \mathrm{a}$ & $65,67 \mathrm{~b}$ & $30,33 \mathrm{cb}$ & $6 \mathrm{~min}$ e 35s d \\
T8h & $168.373 \mathrm{~d}$ & $526,67 \mathrm{a}$ & $81,33 \mathrm{~b}$ & $42,33 \mathrm{a}$ & $13 \mathrm{~min}$ e 59s cd \\
T24h & $68.017 \mathrm{~d}$ & $515,00 \mathrm{a}$ & $196,33 \mathrm{a}$ & $61,67 \mathrm{~b}$ & $18 \mathrm{~min}$ e 33s bc \\
T48h & $70.583 \mathrm{~d}$ & $603,33 \mathrm{a}$ & $107,00 \mathrm{~b}$ & $42,67 \mathrm{c}$ & $32 \mathrm{~min}$ e 03s a \\
T72h & $102.153 \mathrm{~d}$ & $607,33 \mathrm{a}$ & $91,33 \mathrm{~b}$ & $29,33 \mathrm{c}$ & $23 \mathrm{~min}$ e 17s b \\
T96h & $321.090 \mathrm{bc}$ & $695,00 \mathrm{a}$ & $62,67 \mathrm{~b}$ & $27,33 \mathrm{c}$ & $30 \mathrm{~min}$ e 45s a \\
T168h & $482.533 \mathrm{ab}$ & $628,33 \mathrm{a}$ & $54,00 \mathrm{~b}$ & $24,33 \mathrm{c}$ & $6 \mathrm{~min}$ e 14s d \\
T240h & $556.453 \mathrm{a}$ & $755,00 \mathrm{a}$ & $54,67 \mathrm{~b}$ & $29,00 \mathrm{c}$ & $5 \mathrm{~min}$ e 7s d \\
T408h & $439.516 \mathrm{~b}$ & $563,33 \mathrm{a}$ & $59,67 \mathrm{~b}$ & $25,67 \mathrm{c}$ & $7 \mathrm{~min} \mathrm{e} \mathrm{10s} \mathrm{d}$ \\
T576h & $430.687 \mathrm{ab}$ & $590,00 \mathrm{a}$ & $52,67 \mathrm{~b}$ & $28,33 \mathrm{c}$ & $6 \mathrm{~min}$ e 2s d \\
\hline
\end{tabular}

Médias seguidas de letras minúsculas iguais não diferem estatisticamente entre os tempos (Teste

Entre 8 às 72 horas as médias indicam prolongamento do TP e são superiores aos níveis basais $(P \leq 0,05)$ nos bovinos submetidos ao veneno de $B$. alternatus (Tabela 3 ), achado também citado por Sano-Martins et al. (1995) no envenenamento botrópico em cães. O prolongamento de TP confirma a interferência sobre os fatores da coagulação provocada pelo veneno botrópico, devido à estimulação sistêmica desses e formação de trombina intravascular, causando coagulopatia de consumo (Markland, 1998; Theakston e Kamiguti, 1998), pois o teste de TP avalia o passo comum e sistema extrínseco da coagulação (Grubbs et al., 1997). 
As médias do TC oscilaram entre 4 min e $5 \mathrm{seg}$ (0h) até 32 min e 3 seg às 48 horas, sendo significativamente superiores ao valor basal entre 24 às 96 horas após a administração do veneno. O sangue foi considerado incoagulável em 3, 48 e 72 horas após a inoculação, pois quando o TC está acima de 20 ou 30 min há incoagulabilidade sanguínea em seres humanos (Andrade Filho et al., 2001). Este aumento do TC nos bovinos indica alterações provocadas por diversas frações do veneno botrópico que causam consumo de fatores da coagulação, interferência com a função e número de plaquetas, ruptura dos capilares sanguíneos, além de possível ativação do sistema fibrinolítico (Maruyama et al., 2002).

Este resultado em bovinos corrobora as observações feitas em cães expostos ao veneno botrópico por Takahira (1999) e Santos et al. (2003). O consumo de fatores da coagulação é provocado por diversas frações do veneno botrópico como botrocetina e bothrojaracina e alteração da função e número de plaquetas (Roodt et al., 2000).

A média da proteína total variou de 5,75 (0h) a 4,29g/d $\ell, 8$ horas pós-inoculação (Tabela 4). Os valores são inferiores $(p £ 0,05)$ nos tempos 3 e 8 horas, indicando perda de proteínas devido às hemorragias e edema agudo provocados pelo veneno botrópico. As médias são similares ao tempo zero entre 24 e 408 horas após a inoculação do veneno (Tabela 4). A redução de PT sérica após o envenenamento botrópico também foi relatada em seres humanos (Hudelson e Hudelson, 1995) e em cães (Ferreira Jr. e Barraviera, 2004).

Tabela 4: Valores médios da proteína total, albumina e globulinas $(\mathrm{g} / \mathrm{dl})$ séricas em bovinos antes e após a inoculação do veneno de $B$. alternatus $0,15 \mathrm{mg} /$ $\mathrm{kg}$ do veneno por $\mathrm{kg}$ de peso corporal

\begin{tabular}{lccc}
\hline Variável & $\begin{array}{c}\text { Proteína total } \\
(\mathrm{g} / \mathrm{d} l)\end{array}$ & $\begin{array}{c}\text { Albumina } \\
(\mathrm{g} / \mathrm{dl})\end{array}$ & $\begin{array}{c}\text { Globulinas } \\
(\mathrm{g} / \mathrm{dl})\end{array}$ \\
\hline Tempo & & & \\
T0h & $5,75 \mathrm{a}$ & $3,56 \mathrm{a}$ & $2,20 \mathrm{a}$ \\
T3h & $4,38 \mathrm{~b}$ & $2,71 \mathrm{a}$ & $1,66 \mathrm{a}$ \\
T8h & $4,29 \mathrm{~b}$ & $3,15 \mathrm{a}$ & $1,14 \mathrm{a}$ \\
T24h & $4,92 \mathrm{ab}$ & $2,79 \mathrm{a}$ & $2,12 \mathrm{a}$ \\
T48h & $4,75 \mathrm{ab}$ & $2,99 \mathrm{a}$ & $1,75 \mathrm{a}$ \\
T72h & $4,75 \mathrm{ab}$ & $3,08 \mathrm{a}$ & $1,67 \mathrm{a}$ \\
T96h & $5,13 \mathrm{ab}$ & $2,89 \mathrm{a}$ & $2,23 \mathrm{a}$ \\
T168h & $5,24 \mathrm{ab}$ & $3,44 \mathrm{a}$ & $1,80 \mathrm{a}$ \\
T240h & $5,20 \mathrm{ab}$ & $3,13 \mathrm{a}$ & $2,07 \mathrm{a}$ \\
T408h & $5,75 \mathrm{a}$ & $3,43 \mathrm{a}$ & $2,32 \mathrm{a}$ \\
T576h & $5,59 \mathrm{a}$ & $3,41 \mathrm{a}$ & $2,18 \mathrm{a}$ \\
\hline
\end{tabular}

Médias seguidas de letras minúsculas iguais não diferem estatisticamente entre os tempos (Teste SNK $P \leq 0,05$ ).

As médias da albumina sérica nos bovinos variaram entre 3,56 (0h) e $2,71 \mathrm{~g} / \mathrm{d} \ell$, às 3 horas pós-inoculação, não ocorrendo diferença entre estas nos diferentes tempos (Tabela 4). Os valores médios das globulinas séricas foram de 1,14 a 2,32 g/d $\ell$, às 24 e 48 horas respectivamente, após o envenenamento botrópico e foram semelhantes $(P \geq 0,05)$ em todos os tempos.
Apesar de não ultrapassarem os limites de normalidade para a espécie (Kaneko et al., 1997), as médias de AST foram superiores $(P \leq 0,05)$ entre 48 às 240 horas após a inoculação do veneno (Tabela 5), e estes resultados podem estar relacionados com a lesão hepática e/ou muscular provocada por ação direta de proteases e PLA (Kini et al., 2002), metabolização hepática do veneno (Rocha, 1999) e pelo processo flogístico local extenso, descrito por Barraviera et al. (1995).

O aumento da AST nos bovinos inoculados com veneno de $B$. alternatus foi semelhante ao observado em seres humanos (Chaves et al., 1992) e em cães após envenenamento botrópico (Takahira, 1999; Ferreira Jr. e Barraviera, 2004).

Os maiores valores médios de CPT nos bovinos ocorreram entre 24 às 96 horas após a inoculação do veneno, igualando-se aos valores basais somente aos 10 dias (240 horas), indicando a precocidade da CPT quando comparada com a AST, na presença de lesão muscular provocada pelo veneno botrópico. Após 168 horas ocorreu redução gradativa das médias da CPT até 576 horas (Tabela 5). Dal Pai e Santo Neto (1994) e Takahira (1999) também observaram aumento nesta enzima em cães. Esta elevação pode ter sido causada pelos efeitos das $\mathrm{PLA}_{2}$, proteases e metaloproteinases do veneno botrópico na musculatura local (Chaves et al., 2003; Nuñez et al., 2004), ou pode estar relacionada com a lesão muscular distante, provocada por $\mathrm{PLA}_{2}$ de baixa afinidade sistemicamente.

As médias da GGT não apresentaram diferenças (Tabela 5) estatísticas entre os tempos, indicando que, apesar de o veneno botrópico ser metabolizado no fígado, este não foi capaz de causar alterações indicativas de obliteração de ductos biliares em bovinos, semelhante ao relatado em cães por Takahira (1999).

Tabela 5: Valores médios das enzimas (UI/I) aspartato aminotransferase (AST), creatina fosfotransferase (CPT) e gama glutamiltransferase (GGT) e compostos nitrogenados não proteicos séricos $(\mathrm{mg} / \mathrm{dl})$, ureia e creatinina em bovinos antes e após a inoculação do veneno de $B$. alternatus $0,15 \mathrm{mg} /$ $\mathrm{kg}$ do veneno por $\mathrm{kg}$ de peso corporal

\begin{tabular}{|c|c|c|c|c|c|}
\hline Variável & AST UI/I & CPT UI/I & GGT UI/I & $\begin{array}{l}\text { Ureia } \\
\mathrm{mg} / \mathrm{dl}\end{array}$ & $\begin{array}{c}\text { Creatinina } \\
\mathrm{mg} / \mathrm{dl}\end{array}$ \\
\hline \multicolumn{6}{|l|}{ Tempo } \\
\hline TOh & $30,96 \mathrm{bc}$ & $24,06 \mathrm{c}$ & $11,32 \mathrm{a}$ & $27,94 b$ & $0,97 a$ \\
\hline T3h & $26,40 c$ & $22,11 b c$ & $12,99 a$ & $24,38 b$ & $0,75 a$ \\
\hline T8h & $25,90 \mathrm{c}$ & $22,99 \mathrm{bc}$ & $13,27 a$ & $25,91 b$ & $0,77 a$ \\
\hline T24h & $30,00 \mathrm{c}$ & $84,01 a$ & $10,68 a$ & $39,62 b$ & $0,77 a$ \\
\hline T48h & $40,00 a b$ & $94,10 a$ & $11,58 \mathrm{a}$ & $70,09 a$ & $0,70 a$ \\
\hline $\mathrm{T72h}$ & $46,50 \mathrm{a}$ & $95,86 a$ & $11,92 a$ & $39,62 b$ & $0,96 a$ \\
\hline T96h & $45,83 a$ & $89,47 a$ & $9,60 a$ & $35,81 b$ & $0,73 a$ \\
\hline T168h & $40,17 a b$ & $46,87 \mathrm{~b}$ & $14,52 \mathrm{a}$ & $32,76 \mathrm{~b}$ & $0,91 a$ \\
\hline T240h & $42,50 a$ & $38,91 b c$ & $10,68 a$ & $32,00 \mathrm{~b}$ & $0,73 a$ \\
\hline T408h & $25,73 c$ & $32,40 \mathrm{bc}$ & $11,50 a$ & $28,65 b$ & $0,82 a$ \\
\hline T576h & $35,93 a b c$ & $19,26 \mathrm{c}$ & $12,93 a$ & $33,07 \mathrm{~b}$ & $0,90 a$ \\
\hline
\end{tabular}

Médias seguidas de letras minúsculas iguais não diferem estatisticamente entre os tempos (Teste SNK $\mathrm{P} \leq 0,05$ ).

Observou-se elevação significativa da uréia sérica nos bovinos as 48 horas após o envenenamento botrópico experimental (Tabela 5), diferindo dos resultados observados por Takahira, (1999) em cães inoculados com veneno botrópico e tratados com soro antibotrópico. A grande 
sensibilidade do bovino ao veneno botrópico, conforme Araújo e Belluomini (1960-62), quando comparado ao cão, poderiam explicar este resultado, além das diferenças entre protocolos experimentais. $\mathrm{O}$ aumento significativo da ureia às 24 e 48 horas indica uremia associada ao envenenamento botrópico, mesmo não havendo sinais clínicos de insuficiência renal aguda nestes bovinos.

Os valores aumentados de AST até sete dias e ureia às 48 horas pós-inoculação do veneno, demonstram a existência de lesão hepática e uremia pré-renal.

A creatinina sérica média oscilou entre 0,7 (48 horas) a $1,0 \mathrm{mg} / \mathrm{d} \ell(\mathrm{h})$ e não apresentou variação significativa entre os tempos antes e depois da administração do veneno botrópico em bovinos (Tabela 5). Esses resultados são semelhantes aos observados por Takahira (1999), quando

\section{Referências}

ANDRADE FILHO, A.; CAMPOLINA, D.; DIAS, M.B. Ofidismo. In:_. Toxicologia na prática clínica. 2001, Belo Horizonte: Folium. Cap. 32, p. 229-262.

ARAÚJO, P.; BELLUOMINI, E. Toxicidade de venenos ofídicos. I sensibilidade específica de animais domésticos e de laboratório. Mem. Inst. Butantan, v. 30, p. 133-142, 1960-62.

ARAÚJO, P.; ROSENFELD, G.;BELLUOMINI, W. Toxicidade de venenos ofídicos. II- Doses mortais para bovinos. Arquivos do Instituto Biológico, v. 30, p. 43-48, 1963.

BARBOSA, P.S.F; HAVT, A.; FACÓ, P.E.G. et al. Renal toxicity of Bothrops moojeni snake venom and its main myotoxins. Toxicon, v. 40, n. 10, p. 1427-1435, 2002.

BARRAVIERA, B.; LOMONTE, B.; TARKOWSKI, A. et al. Acute-phase reactions, including cytokines, in patients bitten by Bothrops and Crotalus snakes in Brazil. J. Venom. Anim. Toxins, v. 1, n. 1, p. 11 22, 1995.

BIONDO, A.W.; BICUDO, P.L.; KOHAYAGAWA, A. Acidentes ofídicos em medicina veterinária-revisão de 1260 notificações do Instituto Butantan. In: Jornada Científica da Associação de Docentes, 28, Botucatu, 1993, Anais...Botucatu: UNESP, 1993, p. 159 (Resumo).

CARDOSO, J.L.C. Bothropic accidents. Mem. Inst. Butantan, v. 52 (supl.), p. 43-44, 1990.

CARNEIRO, A.S.; RIBEIRO, O.G.; FRANCO, M. et al. Local inflammatory reaction induced by Bothrops jararaca venom differs in mice selected for acute inflammatory response. Toxicon, v. 40, n. 11, p. 1571-1579, 2002.

CASTRO, H.C.; DUTRA, D.L.S.; OLIVEIRA-CARVALHO, A.L. et al. Bothroalternin, a thrombin inhibitor from the venom of Bothrops alternatus. Toxicon, v. 36, n. 12, p. 1903-1912, 1998.

CASTRO, H.C.; FERNANDES, M.; ZINGALI, R.B. Identification of Bothrojaracin-like proteins in snake venoms from Bothrops species and Lachesis muta. Toxicon, v. 37, n. 10, p. 1403-1416, 1999.

CHACUR, M.; LONGO, I.; PICOLO, G. et al. Hyperalgesia induced by Asp49 phospholipases $A_{2}$ from Bothrops asper snake venom: pharmacological mediation and molecular determinants. Toxicon, v. 41, n. 6, p. 667-678, 2003.

CHAVES, F.; GUTIÉRREZ, J.M.; BRENES, F. Pathological and biochemical changes induced in mice after intramuscular injection of venom from newborn specimens of the snake Bothrops asper (Terciopelo). Toxicon, v. 30, n. 9, p. 1099-1109, 1992.

CHAVES, F.; LORÍA, G.D.; SALAZAR, A. et al. Intramuscular administration of antivenoms in experimental envenomation by Bothrops aspercomparison between Fab and IgG. Toxicon, v. 42, n. 2, p. 237-244, 2003. estudou cães inoculados com veneno botrópico. Entretanto, em seres humanos e animais de laboratório já foram descritas alterações renais (Barbosa et al., 2002).

\section{Conclusões}

O veneno de $B$. alternatus $(0,15 \mathrm{mg} / \mathrm{kg}$ de peso corporal) causa intoxicação grave em bovinos, podendo ser letal nesta dosagem para alguns animais.

Bovinos envenenados com $0,15 \mathrm{mg} / \mathrm{kg}$ p.v. de veneno de $B$. alternatus apresentam anemia normocítica normocrômica, leucocitose com neutrofilia com desvio para esquerda regenerativo, linfocitose, aumentos dos tempos de coagulação, de protrombina e de tromboplastina parcial ativada, trombocitopenia e elevação sérica de ureia e das enzimas CPT e AST.

DAL PAI, V.; SANTO NETO, H. Ação dos veenos ofídicos sobres os tecidos animais. In: BARRAVIERA, B. Venenos Animais: uma visão integrada, Rio de Janeiro: Publicações Científicas, 1994, Cap. 8, p. 97-105.

FARSKY, S.H.P.; COSTA-CRUZ, J.W.M.; CURY, Y. et al. Leukocyte response induced by Bothrops jararaca crude venom: in vivo and in vitro studies. Toxicon, v. 35, n. 2, p. 185-193, 1997.

FARSKY, S.H.; GONCALVES, L.R.; CORREA, A.P. et al. Bothrops asper snake venom and its metalloproteinase BaP-1 activate the complement system. Role in leucocyte recruitment. Mediat. Inflamm., v. 9, n. 5, p. 213-221, 2000.

FELDMAN, B.F.; ZINKL, J.G.; JAIN, N.C. (Ed). Schalm's veterinary hematology. 5. ed. Philadelphia: Lippincott Williams e Wilkins, 2000. $1344 \mathrm{p}$.

FERREIRA JR., R.S.; BARRAVIERA, B. Management of venomous snakebites in dogs and cats in Brazil. J. Venom. Anim. Toxins, v. 10, n. 2, p. 112-132, 2004.

FRANCESCHI, J.P. Systemic activites of Bothrops venoms. Mem. Inst. Butantan, v. 52 (supl.), p. 41-42, 1990.

FRANCISCHETTI, I.M.B.; CASTRO, H.C.; ZINGALI, R.B. Bothrops sp. Snake venoms; comparison of some biochemical and physiochemical properties and interference in platelet functions. Comp. Biochem. Physiol,v. 119c, n. 1, p. 21-29, 1998.

GRUBBS, S.T.; OLCHOWY, T.W.J. Bleending disorders in cattle: a review and diagnostic approach. Vet. Med., v. 92, n. 8, p. 737-743, 1997.

HOLLOWAY, S.A.; PARRY, B. Observations on blood coagulation after snakebite in dogs and cats. Aust. Vet. J., v. 66, n. 11, p. 364366, 1989.

HUDELSON, S; HUDELSON, P. Pathophysiology of snake envenomization and evaluation of treatments-Part I. Comp. Cont. Educ. Pract. Vet., v.17, n. 7, p. 799-896, 1995.

JÁCOME, D., MELO, M.M., SANTOS, M.M.B. et al. Kinetics of venom and antivenom serum and clinical parameters and treatment efficacy in Bothrops alternatus envenomed dogs. Vet. Hum. Toxicol., v. 44, n. 6, p. 334-338, 2002.

KANEKO, J.J.; HARVEY, J.W.; BRUSS, M.L. (Ed.). Clinical biochemistry of domestic animals. 5. ed. San Diego: Academic Press, 1997. 932 p.

KAMIGUTI, A.S.; HAY, C.R.M.; THEAKSTON, R.D.G. et al. Insights into the mechanism of haemorrhagic caused by snake venom metalloproteinases. Toxicon, v. 34, n. 6, p. 627-642, 1996.

KAMIGUTI, A.S.; SLUPSKY, J.; ZUZEL, M. et al. Properties of fibrinogen cleaved by jararhagin, a metalloproteinase from the venom of Bothrops jararaca. Thromb. Haem., v. 72, n. 2, p. 244-249, 1994. 
KELLEN, E.M.A.; ROSENFELD, G.; NUDEL, F. Hemolytic activity of animal venoms. II Variation in relation to erythrocyte especies. Mem. Inst. Butantan, v. 30, p. 133-142, 1960-62.

KINI, R.M. Excitement ahead: structure, function and mechanism of snake venom phospholipase $\mathrm{A}_{2}$ enzime. Toxicon, v. 42, n. 8, p. 827840, 2002.

LAGO, L.A.; MELO, M.M.; FERREIRA, P.M. et al. Alterações hematológicas em bovinos submetidos ao envenenamento crotálico experimental (Crotalus durissus terrificus-crotamina positivo). Rev. Bras. Saúde Prod. Anim. v. 1, p. 7-13, 2001.

LEE, R.I.; WHITE, P.D. A clinical study of the coagulation time of blood. Am. J. Med. Sci, v. 145, p. 495-503, 1913.

MARIA, D.A.; VASSÃO, R.C.; RUIZ, I.R.G. Haematopoietic effects induced in mice by the snake venom toxin jararhagin. Toxicon, v. 42, n. 6, p. 579-585, 2003.

MARKLAND, F.S. Snake venom and hemostatic system. Toxicon, v. 36, n. 12, p. 1-58, 1998.

MARUYAMA, M.; SUGIKI, M.; ANAI, K. et al. N-terminal amino acid sequences and some characteristics of fibrinolytic/hemorrhagic metalloproteinases purified from Bothrops jararaca venom. Toxicon, v. 40, n. 8, p. 1223-1226, 2002.

MENEZES, R.V. Ofidismo em bovinos. Arq. Esc. Med. Vet. UFBA, v. 18, n. 1, p. 224-231, 1995.

MILLER, R.A.; TU, A.T. Factors in snake venoms that increase capillary permeability, J. Pharm. Pharmacol., v. 41, p. 792-794, 1989.

MURATA, H.; SHIMADA, N.; YOSHIOKA, M. Current research on acute phase proteins in veterinary diagnosis: an overview. Vet. Journal, v. 168, n. 1, p. 28-40, 2004.

OLIVEIRA, N.J.F., MELO, M.M., LARA, E.R. et al. Perfil clínico e imunológico de bovinos experimentalmente inoculados com veneno bruto e iodado de Bothrops alternatus. Arq. Bras. Med. Vet. Zootec., v. 59, n. 3, p. 569-576, 2007.

OTERO, R.; GUTIÉRREZ, J.; MESA, M.B. et al. Complications of Bothrops, Porthidium and Bothriehis snakebites in Colombia. A clinical and epidemiological study of 39 cases attendend in a university hospital. Toxicon, v. 40, n. 8, p. 1107-1114, 2002.

PÉREZ, O.C.A.; KOSCINCZUK, P.; FLINTA, S.M. et al. Bothrops alternatus envenoming in young dogs. J. Venom. Anim. Toxins, v. 3, n. 1, p. 43-47, 1997.

PÉREZ, O.C.A; KOSCINCZUK, P.; TEIBLER, P. et al. Actividades hemorrágica y edematizante y alteraciones histológicas em almohadilla plantar del ratón inducidas por venenos de serpientes de los géneros Bothrops y Crotalus de Argentina. Toxicon, v. 36, n. 8, p. 1165-1172, 1998.
RATNOFF, M.D.; CALVIN MENZIE, A.B. A new method for the determination of fibrinogen in small samples of plasma. J. Lab. Clin. Med., v. 37, p. 316-320, 1951.

ROCHA, M.L. The distribution and elimination of Bothrops erythromelas venom labeled with $\mathrm{I}^{131}$ after intravenous injection in mice. J. Venom. Anim. Toxins, v. 5, n. 1, p. 99, 1999.

ROODT, A.R.; DOLAB, J.A.; DOKMETJIAN, J.C.H. et al. A comparison of different methods to assess the hemorrhagic activity of Bothrops venoms. Toxicon, v. 38, n. 6, p. 865-873, 2000.

ROSENFELD, G.; KELEN, M.A.; NUDEL, F. Hemolytic activity of animal venoms. I-Classification in different types and activites. Mem. Inst. Butantan, v. 30, p. 103-116, 1960-62.

SAMPAIO, I. B. M. Estatística aplicada à experimentação animal. 3. ed. Belo Horizonte: Fundação de Ensino e Pesquisa em Medicina Veterinária e Zootecnia, 2007, 264 p.

SANTOS, M.M.B; MELO, M.M.; JACOME, D.O. et al. Hemograma de cães envenenados experimentalmente com Bothrops alternatus após diferentes tratamentos. Rev. Bras. Saúde Prod. An., v. 4, n. 1, p. 1-11, 2003.

SANO-MARTINS, I.S.; SANTORO, M.L.; MORENA, P. etal. Hematological changes induced by Bothrops jararaca venom in dogs. Braz. J. Med. Biol. Res., v. 28, p. 303-312, 1995.

SANO-MARTINS, I.S.; SANTORO, M.L.; CASTRO, S.C.B. et al. Platelet aggregation in the patients bitten by the Brazilian snake Bothrops jararaca. Thromb. Res., v. 87, n. 2, p. 183-195, 1997.

SEGEV, G.; SHIPOV, A.; HARRUS, S. et al. Vipera palaestinae envenomation in 327 dogs: a retrospective cohort study and analysis of risk factors for mortality. Toxicon, v. 43, n. 6, p. 691-699, 2004.

SUGIKI, M.; MARUYAMA, M.; YOSHIDA, E. Enhancement of plasma fibrinolysis in vitro by jararhagin, the main haemorragic metaloproteinase in Bothrops jararaca venom. Toxicon, v. 33, n. 12, p. 1605-1617, 1995.

TAKAHIRA, R.K. Perfil hematológico, hemostático, bioquímico e histopatológico do envenenamento experimental de cães por Bothrops alternatus (Duméril, 1854) e Bothrops moojeni (Hoge, 1966). 1999. 195 f. Tese (Doutorado)-Faculdade de Medicina Veterinária e Zootecnia, Universidade Estadual Paulista, Botucatu, SP.

TANJONI, I.; BUTERA, D.; BENTO, L. et al. Snake venom metalloproteinases: structure/ function relationships studies using monoclonal antibodies. Toxicon, v. 42, n. 7, p. 801-808, 2003.

THRALL, M.A. Veterinary hematology and clinical chemistry. Philadelphia: Lippincott Williams \& Wilkins, 2004. 561 p.

THEAKSTON, R.D.G.; KAMIGUTI, A.S. Viper envenoming: evaluation of treatment by restoration of haemostasis and venom clearance. $J$. Venom. Anim. Toxins, v. 4, n. 2, p. 94-111, 1998. 